\title{
Achieving Esthetics with Andrew's Bridge
}

\author{
${ }^{1}$ Prasan Kumar Kolaganti, ${ }^{2}$ Shubha Joshi, ${ }^{3}$ BN Shalini, ${ }^{4}$ Sowjanya Kolaganti, ${ }^{5} \mathrm{G}$ Jesudass
}

\begin{abstract}
The anterior ridge defects present in a patient are very difficult to treat and they require great amount of planning, like removable or fixed prosthesis and options of implant. Here is a article that describes the process of fabrication of Andrew's bridge to treat a class III anterior ridge defect using natural teeth as abutments for its fixed component followed by a removable component. The procedure of fabricating Andrew's bridge was undertaken when a 26 years old patient came to the department of prosthodontia after being operated for the cleft lip and palate. After the patient was treated with this Andrew's bar system, it was evaluated over a long period of time and accordingly it was concluded that the patient had a good adaptability, comfort, pleasing esthetics and phonetics were achieved as desired and can be given in patients where esthetics due to repositioning of teeth creates difficulties.
\end{abstract}

Keywords: Andrew's bridge, Class III ridge defect, Cobaltchromium alloy, Bar attachment.

How to cite this article: Kolaganti PK, Joshi S, Shalini BN, Kolaganti S, Jesudass G. Achieving Esthetics with Andrew's Bridge. Int J Prosthodont Restor Dent 2014;4(4):127-130.

\section{Source of support: Nil}

\section{Conflict of interest: None}

\section{INTRODUCTION}

The anterior ridge defects pose very difficult problems to treat with respect to esthetics and phonetics. These defects have been treated with great amount of planning and complexity while using the conventional treatment approaches, like removable or fixed prosthesis and options of implant. Sibert (1983) identified three basic ridge deformities: buccolingual loss of tissues (class I), apicocoronal loss of tissues (class II) and combination of buccolingual and apicocoronal loss of tissues (class III). ${ }^{1}$

\footnotetext{
${ }^{1}$ Assistant Professor, ${ }^{2}$ Senior Lecturer, ${ }^{3}$ Reader

${ }^{4}$ Senior Resident, ${ }^{5}$ Associate Professor

${ }^{1,4}$ Department of Dentistry, Rangaraya Medical College Kakinada, Andhra Pradesh, India

${ }^{2,3}$ Department of Prosthodontics, AMES Dental College Raichur, Karnataka, India

${ }^{5}$ Department of Pedodontics, Government Dental College and Hospital, RIMS, Kadapa, Andhra Pradesh, India

Corresponding Author: Prasan Kumar Kolaganti, Assistant Professor, Department of Dentistry, Rangaraya Medical College Kakinada, Andhra Pradesh, India, Phone: 09700032087 e-mail: prashantkola@gmail.com
}

The Andrew's bridge tends to be the best option for cleft palate patients with congenital or acquired defects. This is designed to meet the requirements for esthetics, comfort, phonetics, hygiene and favorable stress distribution to the abutments and soft tissue. The design consists of two porcelain-fused-to-metal (PFM) crowns that fits over the abutments and both are connected by a bar that runs over the ridge. This assembly is permanently cemented to the prepared abutment, while the missing teeth were replaced by removable pontics with a metal sleeve tract embodied within an acrylic removable partial denture.

\section{CASE REPORT}

A 26-year-old patient male patient was referred to our department from department of oral surgery after being treated for the cleft palate. He was previously treated for primary and secondary staged surgeries for cleft lip palate and nasal defects. Also, augmentation rhinoplasty was done using costochondral graft (Fig. 1). He presented with a class III ridge defect for which he was not willing for further graft surgeries. His main concerned was esthetics. Medical history revealed no contraindication for dental treatment.

Extraoral examination indicated slight asymmetry in upper lip, straight profile, exposure of gingival cleft while smiling, intraoral examination revealed class III ridge defect, good oral hygiene. He was planned for Andrew's bridge using both the maxillary canine as abutments and a removable partial denture for the four missing anteriors (Fig. 2).

\section{MATERIALS AND METHODS}

Diagnostic casts were prepared using an alginate (Dentsply) as impression material. Facebow transfer was done using Whipmix articulator. The abutment teeth were prepared for metal ceramic crowns and another impression were recorded using the putty wash technique using polyvinyl siloxane (Dentsply_Aquasil Putty Material) and master casts were poured in dental stone (type IV) (Fig. 3) and temporization was done (Fig. 4).

Wax patterns were made on the prepared teeth, and the bar was also fabricated using pattern wax which was adapted according to the curvature of the ridge and was attached to the abutment teeth as posteriorly as possible (Fig. 5). The whole pattern was then casted in chrome 


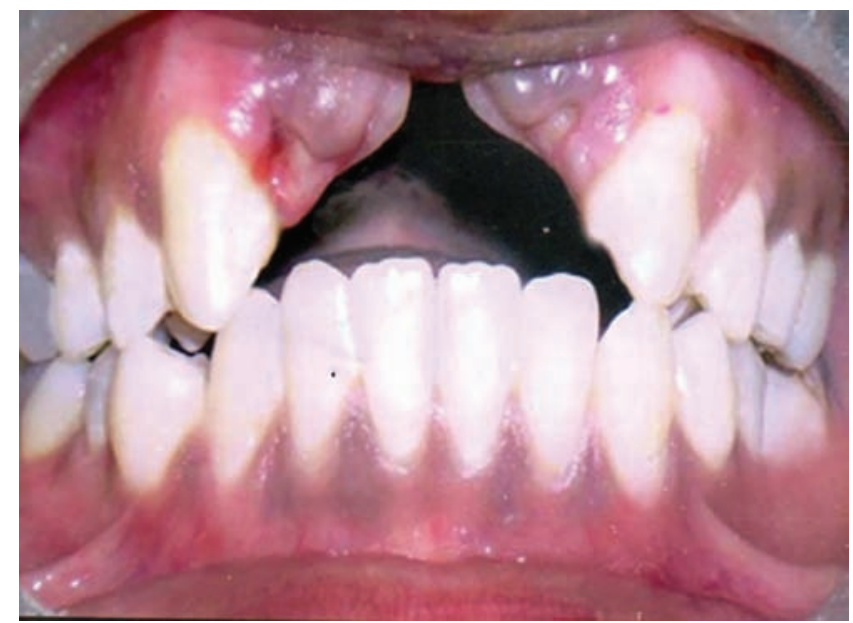

Fig. 1: Preoperative view

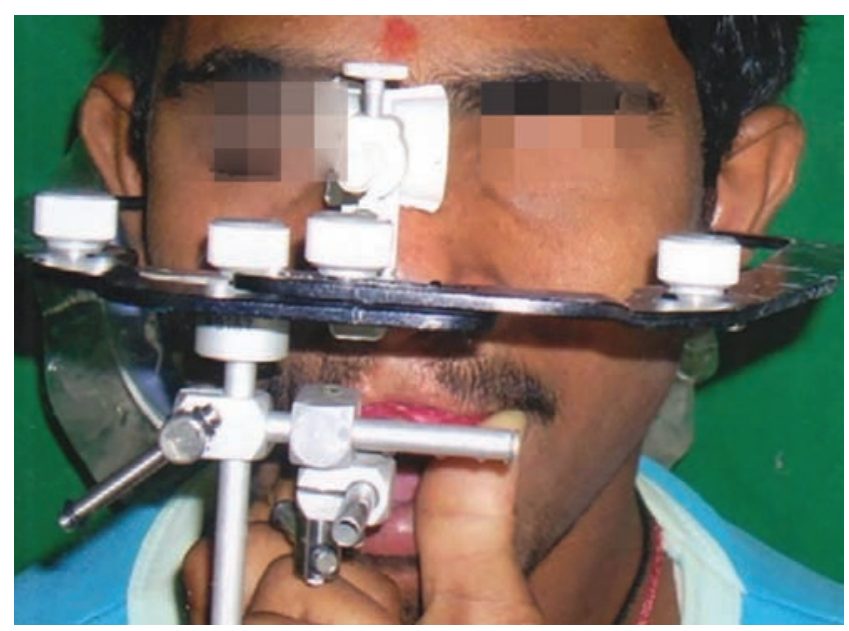

Fig. 3: Facebow transfer

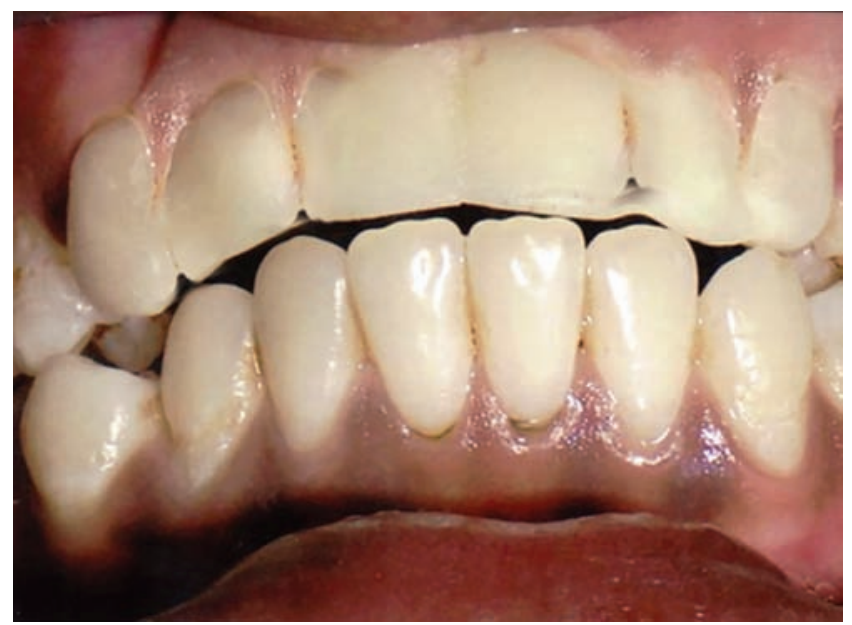

Fig. 5: Temporization done

cobalt alloy, and this metal framework was tried in the patient's mouth and was checked for clearance between the bar attachment and underlying soft tissues (Fig. 6).

Shade selection was done, and the restorations were finished and polished.

Then with the crowns in position, along with the bar, an alginate impression was made, and a stone cast was poured (Fig. 7). Later on, the missing teeth were arranged

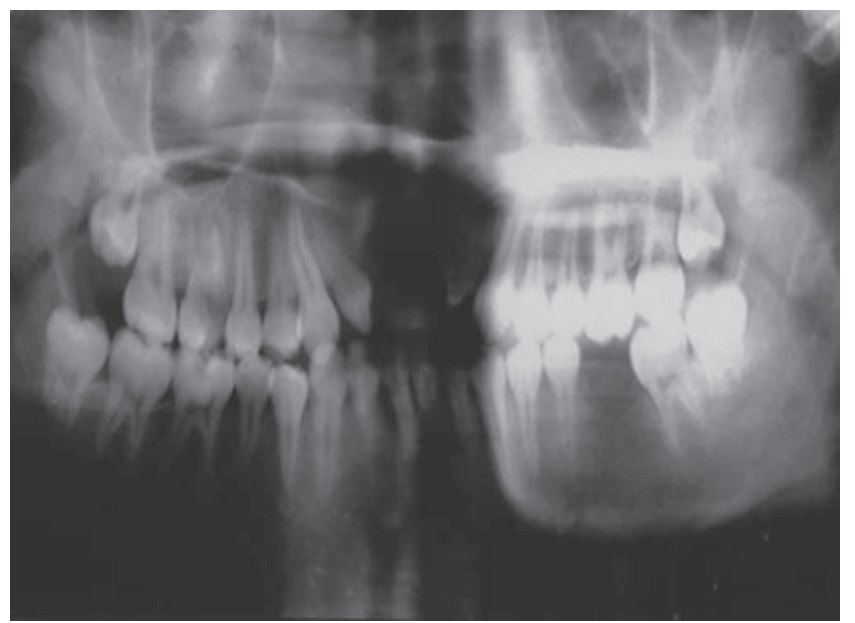

Fig. 2: Orthopantomography

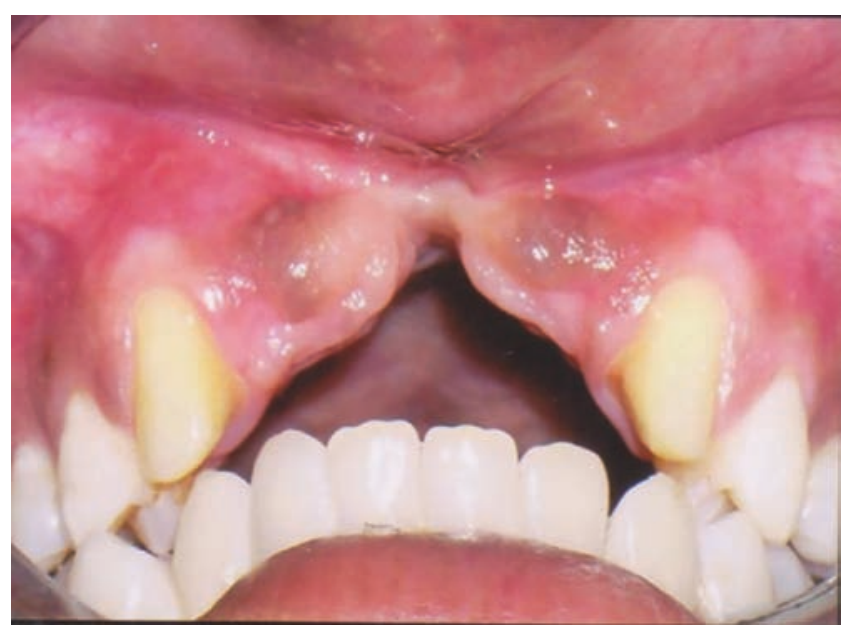

Fig. 4: Tooth preparations done

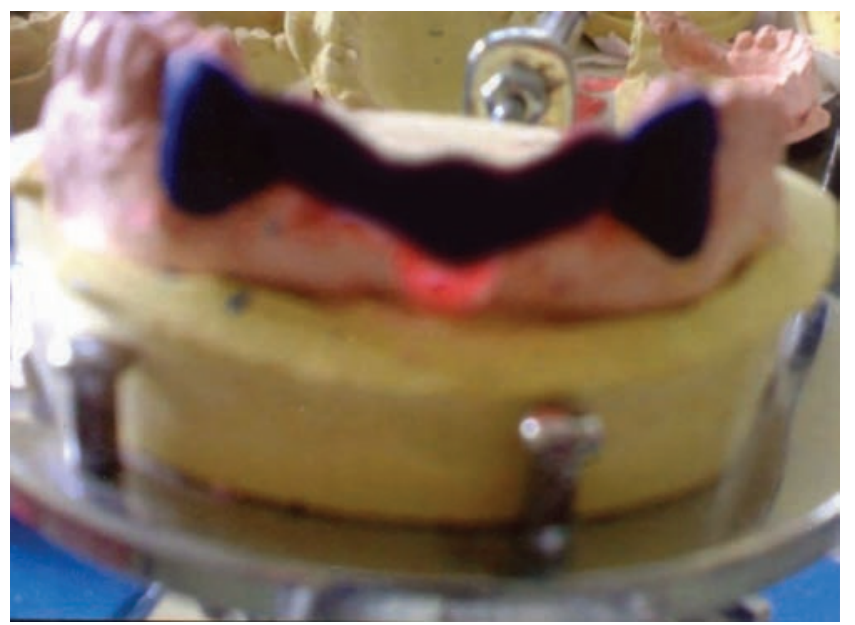

Fig. 6: Wax-up done

in the wax rim and trial was done, which was further replaced by pink colored heat-cured acrylic resin with a clip placed in the lingual aspect to attach this removable partial denture (RPD) over the bar attachment (Fig. 8).

Following which patients were trained to properly place and remove the RPD fabricated over the fixed component of Andrew's bridge, and proper oral hygiene instructions were given to the patient (Figs 9 and 10). 


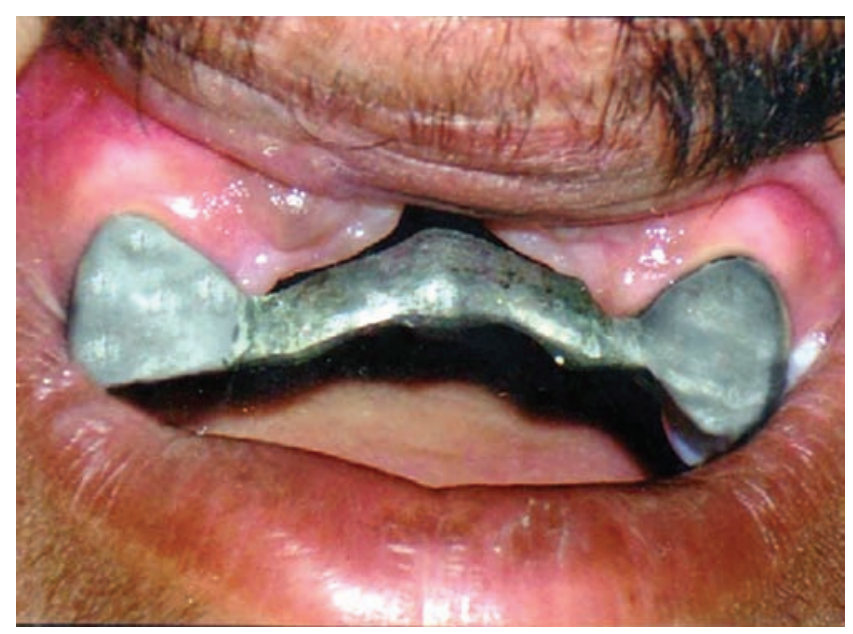

Fig. 7: Metal try-in

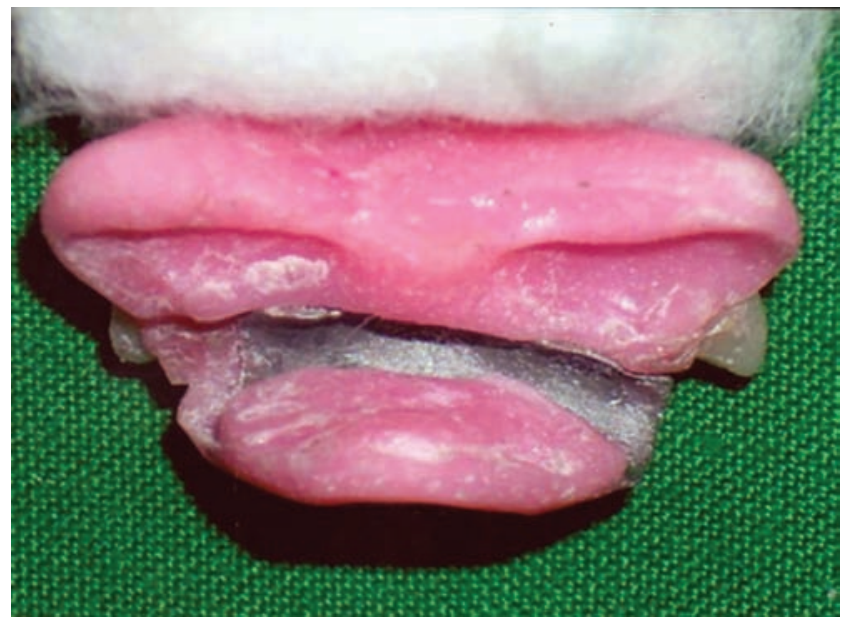

Fig. 9: Acrylic resin with a clip placed

Periodic recall was done to check for the adaptability and assess the success of the treatment.

\section{DISCUSSION}

During treatment planning, case selection is the important part of the treatment as there was severe bone loss. The esthetic replacement of anterior teeth is a difficult challenge, especially in the maxillary arch. This situation can be further complicated by the presence of a ridge deformity. These anatomic defects may seriously compromise the esthetics of the final restoration. All the treatment choices were explained to the patient; after the patients' final decision, the Andrew's bridge was the treatment of choice.

Though there are many esthetic treatment options, the major prosthetic treatments chosen to close the softtissue defect are removable flange prostheses, Andrew's bridge. Conventional fixed pontics need to be designed for self cleansing in situ and also to avoid ulceration during flossing. Replacing papilla in between pontics is difficult and unreplaced papilla appears unnatural and invite food lodgment. Fixed bridges may also result

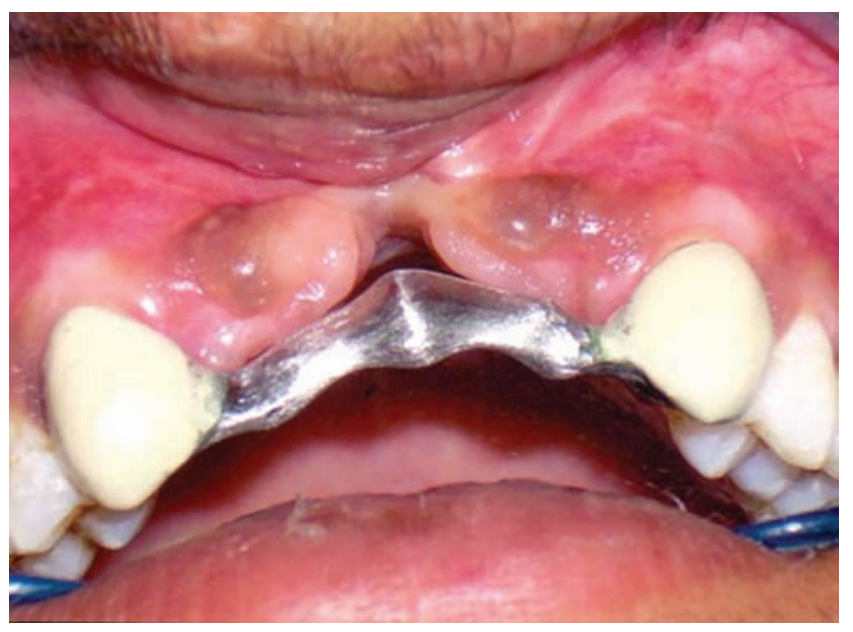

Fig. 8: Crowns in position, along with the bar

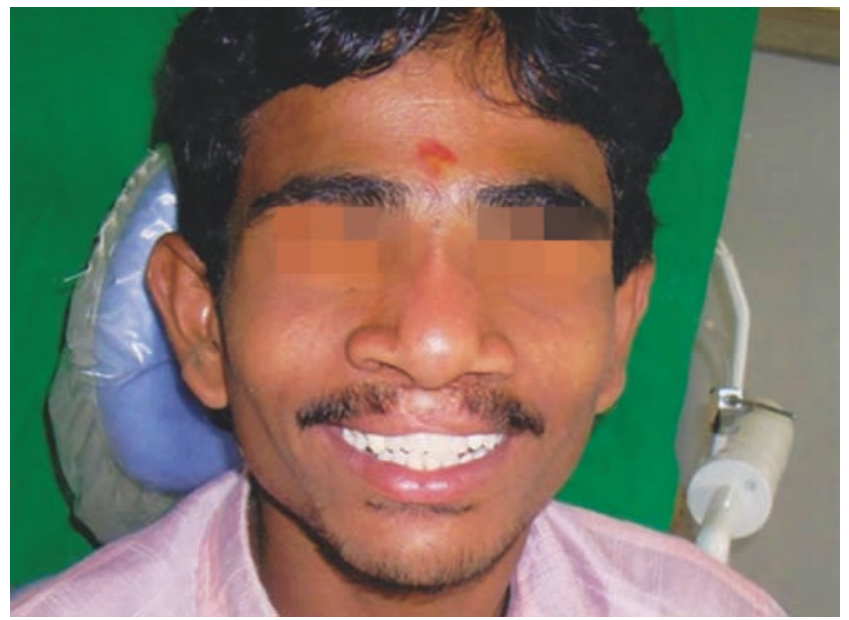

Fig. 10: Postoperative view

in black triangles which are esthetically unpleasing. Unlike Andrew's bridge, all the forces are borne by the abutments. The seating and close adaption of acrylic saddle on the ridge absorbs forces. Curved bars ensure that lifting and depressing forces are shared by all sectors. Acrylic teeth and the flange absorb force and do not allow attrition of opposing teeth. Andrew's bar and sleeve offer values that no other attachment can. The frictional fit of walls of bars and sleeves provides retention. ${ }^{1}$

Andrew's bridge is indicated when there is:

- Excessive residual ridge defect.

- Ridge defects/jaw defects either due to trauma and/ or surgical ablation.

- Cleft palate patients with congenital or acquired defects.

Advantages of Andrew's bridge include better esthetics, hygiene along with better adaptability and phonetics. It is comfortable and economical for patients. There is no plate as in RPD. ${ }^{2}$ No soft-tissue impingement and the surrounding structures. The system acts as stress breaker while transmitting unwanted leverage forces. A new pontic can be redone if necessary without disturbing 
the cemented abutments. Another favorable criterion of the Andrew's bar system is that it can be removed by the patient for hygienic access to the abutments and surrounding tissues. ${ }^{3}$ The Andrew's bridge is more stable and retentive because it is completely tooth borne, and the occlusal forces are also directed toward the long axis of the supporting teeth. The flange of the pontic assembly is contoured to improve comfort, esthetics and phonetics, and to resist possible torque during function. Moreover, in contrast to conventional fixed partial dentures, the pontic assembly is removed to facilitate hygiene procedures and may be relined as the ridge resorbs. ${ }^{4}$ The removable partial denture for class IV cases though considered as a simple treatment option, involves more lever action equal to the Kennedy's class I situations. ${ }^{5}$ The removable partial denture design also involves placement of clasps in the esthetic zone which is not desirable for a young female patient. ${ }^{6}$ Recently, spark-erosion technology has been introduced in dentistry. It is made of a primary bar casting joining the implants and a removable metal superstructure upon which the replacement teeth are processed. The precise fit of the secondary restoration over the primary bar casting and the rigid fixation with the spark eroded attachment dictate that the restoration becoming viewed as totally implant supported. Both the Andrew's bar system and the spark-erosion overdenture share the similarity of having the advantages of the totally implant-supported fixed partial denture and the implantsupported overdenture.

However, the inherent problems associated with the fabrications of spark-erosion overdenture may limit the availability of the technology to the profession because they require high laboratory precision, are bulky and tend to wear out. ${ }^{7}$

The Andrew's system is usually of two types based on the area of bar attachment as follows:

- Pontic-supported.

- Bone anchored or implant-supported Andrew's bar system. ${ }^{8}$
In case of pontic-supported Andrew's bridge, the bar and sleeve provides retention, this allows pontic to seat on the ridge before the sleeve bottoms out on the bar preventing full bar seating. ${ }^{9}$ It also allows pontic to be entirely ridge borne.

\section{CONCLUSION}

The pontic supported Andrew's bar system is particularly indicated for patients with extensive supportive tissue loss and when alignment of opposing arch and esthetic arch position of the replacement teeth create difficulties. The Andrew's bar system provides maximum esthetics, maximum hygienic, optimum loading conditions and minimum trauma to the soft tissue incomparable fit and is very economic.

\section{REFERENCES}

1. Andrew JA, Biggs WF. The Andrews bar-and-sleeve-retained bridge: a clinical report. Dent Today 1999 Apr;18(4):94-99.

2. Shankar RY, et al. A fixed removable partial denture treatment for severe ridge defect. Int J Dent Case Reports 2011; 1(2):112-118.

3. Sadig MW. Bone anchored Andrew's bar system: a prosthetic alternative. Cairo Dent J 1995;11(1):11-15.

4. Mueninghoff LA, Johnson MH. Fixed-removable partial denture. J Prosthet Dent 1982;48(5):547-550.

5. DeBoer J. Edentulous implants: overdenture versus fixed. J Prosthet Dent 1993;69(4):386-390.

6. McGivney GP, Castleberry DJ. Principles of removable partial denture design. In: Reinhardt W, editor. Text book of McCracken's Removable Partial Prosthodontics. 8th ed. New Delhi: CBS Publishers; 1989. p. 157-182.

7. Salinas TJ, Finger IM, Thaler JJ 2nd, Clark RS. Spark-erosion implant-supported overdentures: clinical and laboratory techniques. Implant Dent 1992;1(4):246-251.

8. Kaurani P, Samra RK, Kaurani M, Padiyar N. Prosthodontic rehabilitation of a case with an anterior ridge defect using Andrew's bridge. Ind J Dent Sci 2013 Jun;2(5): 100-103.

9. Muthuvignesh J, Bhuminanthan S, Egammai S, Donapati NR. Improving facial esthetics with Andrew's bridge: a clinical report. Ind J Multidis Dentist 2013 Nov;1(4): 884-887. 